\title{
O GRAFISMO INFANTIL E SUA RELAÇÃO COM A ESCRITA: uma experiência vivida na Associação Pestalozzi de Codó - MA
}

\author{
CHILDREN'S GRAPHISM AND ITS RELATIONSHIP \\ WITH WRITING: an experience lived at the Pestalozzi \\ Association of Codó - MA
}

\section{EL GRAFISMO INFANTIL Y SU RELACIÓN CON LA ESCRITURA: una experiencia vivida en la Asociación Pestalozzi de Codó - MA}

iD Maria de Fátima Braga Novaes Universidade Federal do Maranhão (UFMA), campus Codó, Codó, Maranhão, Brasil. E-mail: fatimabraganovaes@gmail.com

(iD) Cristiane Dias Martins da Costa Universidade Federal do Maranhão (UFMA), campus Codó, Codó, Maranhão, Brasil. E-mail: crisdmc@gmail.com

Resumo: O artigo aborda a relação estabelecida entre o grafismo infantil, produzido por alunos da Associação Pestalozzi de Codó - Maranhão, e as fases de aquisição da escrita alfabética. Nesse contexto, a metodologia teve como enfoque o estudo de caso de cunho etnográfico, considerando a imersão na escola durante dois anos. O apoio teórico ancora-se em estudiosos do campo do grafismo infantil, como Ferreira (2015), Hanauer (2013) e Yavorsti (2018), e da evolução da escrita, como Ferreiro e Teberosky (1999), Luna e Silva (2013), Rosseto (2017), entre outros. Através da pesquisa, constatou-se que o grafismo contribui para o processo de ensino da criança, pois permite à criança externar graficamente suas necessidades, sentimentos, além de contribuir com aspectos cognitivos, motores, sociais e emocionais.

Palavras- chave: Escrita infantil. Desenho infantil. Psicogênese da leitura e da escrita. 
Abstract: The article addresses the relationship established between children's graphics, produced by students from the Pestalozzi Association of Codó - Maranhão, and the phases of acquisition of alphabetical writing. In this context, the methodology focused on the case study of an ethnographic nature, considering immersion in school for two years. Theoretical support is based on scholars in the field of children's graphics Ferreira (2015), Hanauer (2013), Yavorsti (2018) and the evolution of writing Ferreiro and Teberosky (1999), Luna and Silva (2013), Rosseto (2017) between others. Through research, it was found that graphics contribute to the child's teaching process, as it allows children to graphically express their needs, feelings, in addition to contributing with cognitive, motor, social and emotional aspects.

Keywords: Children's writing. Childish drawing. Art.

Resúmene: El artículo aborda la relación que se establece entre la gráfica infantil, producida por estudiantes de la Asociación Pestalozzi de Codó - Maranhão, y las fases de adquisición de la escritura alfabética. En este contexto, la metodología se centró en el estudio de caso de carácter etnográfico, considerando la inmersión en la escuela durante dos años. El apoyo teórico se basa en estudiosos del campo de la gráfica infantil Ferreira (2015), Hanauer (2013), Yavorsti (2018) y la evolución de la escritura Ferreiro y Teberosky(1999), Luna y Silva (2013), Rosseto (2017) entre otros. A través de la investigación, se encontró que la gráfica contribuye al proceso de enseñanza del niño, ya que permite a los niños expresar gráficamente sus necesidades, sentimientos, además de contribuir con aspectos cognitivos, motores, sociales y emocionales.

Palabras clave: Escritura infantil. Dibujo infantil. Arte.

Submetido em 28 de fevereiro de 2021.

Aceito em 04 de junho de 2021.

Publicado em 21 de janeiro de 2022. 


\section{Introdução}

O desenho infantil é uma atividade pedagógica envolvente e de grande importância para o desenvolvimento intelectual, emocional e social da criança. É por meio do grafismo que surgem as primeiras expressões gráficas produzidas pelo ser humano, antes mesmo do contato com o ambiente escolar. Além disso, esta atividade também contribui para a criança externar fatos reais ou imaginários, uma vez que este tipo de arte permite a ela expressar sentimentos, anseios e sua representação da escrita, antes mesmo de ter o conhecimento do alfabeto. É, também, um dos recursos didáticos que pode auxiliar o professor dentro de sala de aula, pois, a partir do momento em que o professor passa a olhar o grafismo com mais perspicácia e não como passatempo, o processo de ensino se torna mais dinâmico e significativo para a criança.

Nesse sentido, a pesquisa teve como objetivo apresentar a relação do grafismo infantil com a escrita alfabética de crianças do segundo ano, anos iniciais do Ensino Fundamental da Associação Pestalozzi de Codó. A escola atende cerca de 203 crianças, jovens e adultos com algum tipo de deficiência, mas a pesquisa foi realizada em apenas uma turma do turno matutino a partir das atividades do projeto de extensão "Alfabetização e Letramento na Educação Especial" do Curso de Pedagogia da Universidade Federal do Maranhão, Campus Codó. Para tanto, o desenvolvimento da mesma aconteceu da seguinte forma: participação no projeto durante dois anos, com início no mês de agosto do ano de 2019, sendo realizada na Escola Lalá Ramos, mais conhecida na cidade de Codó como Pestalozzi; e pesquisa bibliográfica, que forneceu apoio teórico através de leituras em documentos de referência norteadores para Educação Básica, periódicos, monografias, dissertações e livros que envolvem a temática em análise.

No primeiro momento da pesquisa na escola, as atividades realizadas foram por meio da participação nas contações de história do Projeto "Clássicos da literatura infantil: uma viagem no 
mundo da imaginação", que aconteciam todas as segundas-feiras para todos os alunos do turno matutino da Pestalozzi. Concomitantemente às contações, foram realizadas na turma do $2^{\circ}$ ano observações e realização de atividades de desenho direcionado a partir das histórias contadas. As atividades de observação e regência foram desenvolvidas nessa turma, no turno matutino, com dez crianças, todos os alunos são pessoas com deficiência (PCD).

Quanto à análise dos dados, que foi feita a partir das observações dos desenhos das crianças e de sua relação com a escrita alfabética, se baseou na abordagem qualitativa. Ferreira, C. (2015, p. 117) ressalta que a pesquisa qualitativa "é essencial para o entendimento da realidade humana, das dificuldades vivenciadas, das atitudes e comportamentos dos sujeitos envolvidos, constituindo-se um suporte teórico essencial". Sendo assim, mediante essa abordagem, a aproximação entre colaborador e pesquisador é dialógica e contribui para conhecer de perto como é a realidade dos colaboradores da pesquisa.

A pesquisa qualitativa tem como objetivo explorar o ambiente investigado; "é um estudo preliminar voltado a familiarizar o pesquisador com o fenômeno sob investigação" (PAIVA, 2019, p. 13), possibilitando a familiaridade com o assunto em análise, objetivando o conhecimento de maneira mais profunda e esclarecedora, com ideias articuladas para encontrar respostas ao problema da pesquisa. O pesquisador no decorrer da pesquisa, como ressalta Paiva (2019), é um observador participante, pois pode auxiliar o professor dentro da sala de aula, podendo até substituí-lo quando for o caso. Devido a esse contato próximo com os envolvidos na pesquisa, o pesquisador tem liberdade para expressar sua opinião.

Pesquisas de natureza qualitativa envolvem uma grande variedade de materiais empíricos, que podem ser estudos de caso, experiências pessoais, histórias de vida, relatos de introspecções, produções e artefatos culturais, interações, enfim, materiais que descrevam a rotina e os significados da vida humana em grupos. A metodologia vivenciada nesta pesquisa teve como enfoque o estudo de caso de cunho etnográfico, considerando a imersão no am- 
O GRAFISMO INFANTIL E SUA RELAÇÃO COM A ESCRITA: uma experiência vivida... Maria de Fátima Braga Novaes • Cristiane Dias Martins da Costa

biente escolar durante dois anos. Conforme Wielewicki (2001), a pesquisa etnográfica é um método que o pesquisador utiliza para estudar os povos e sua cultura em um determinado ambiente, descrevendo suas similaridades e compartilhando conhecimento.

Vale ressaltar a importância da fundamentação teórica para a realização desta pesquisa, recorrendo a estudiosos do campo do grafismo infantil, como Ferreira, A. (2015), Hanauer (2013) e Yavorsti e Campos (2018), e da evolução da escrita, como Ferreiro e Teberosky (1999), Luna e Silva (2013), Rosseto (2017), dentre outros. Para Severino (2007), a pesquisa bibliográfica realiza-se por registros disponíveis, decorrente de pesquisas anteriores, em documentos impressos, como livros, artigos, teses etc. Dessa forma, os artigos, livros e pesquisas serviram de apoio para a fundamentação teórica desta pesquisa.

Nesse contexto, é importante salientar que, para uma melhor compreensão do leitor, este trabalho será estruturado da seguinte forma: na primeira seção, aspectos sobre a relação do grafismo com a escrita alfabética serão pontuados, dando ênfase a algumas características que existem entre essas duas formas gráficas; no item seguinte, apresenta-se características sobre o campo de pesquisa e, posteriormente, discorre-se sobre os desenhos em sala de aula, a análise e apresentação dos desenhos produzidos pelas crianças e sua relação com a escrita alfabética.

\section{O GRAFISMO INFANTIL E A ESCRITA ALFABÉTICA: linguagens que se complementam}

A arte está presente no dia a dia do homem desde muito tempo; seja representada de forma simples ou mais elaborada, tem sempre o mesmo objetivo, estabelecer uma comunicação visual entre as pessoas. Nesse contexto, uma das primeiras formas gráficas que o homem utilizou em seu dia a dia para diversos fins foi o grafismo, e por meio deste é possível até os dias atuais expressar diferentes situações em que o ser humano está envolvido. Sob 
O GRAFISMO INFANTIL E SUA RELAÇÃO COM A ESCRITA: uma experiência vivida...

Maria de Fátima Braga Novaes • Cristiane Dias Martins da Costa

essa perspectiva, Marques (2016) enfatiza que mediante o grafismo o homem expõe seus anseios, sua imaginação, sentimentos e fatos do seu dia a dia.

Nessa perspectiva, é importante ressaltar que, segundo o dicionário online de Português, a palavra grafismo tem os seguintes significados: "Técnica que consiste na elaboração de traçados preparatórios para a escrita, desprovidos de qualquer significação. [..] Modo de traçar uma linha, de desenhar"1. Sendo assim, o grafismo pode ser utilizado pela criança como base para o desenvolvimento da escrita alfabética nos seus primeiros momentos de elaboração da escrita, pois antes de ter o domínio desse código escrito alfabético, a criança faz uso desse recurso gráfico para poder expressar diferentes comportamentos.

O início do processo de aquisição da escrita pela criança perpassa também diversas fases, sendo assim, Lucas, Custódio e Vidotti (2012), quando relacionam o grafismo com a escrita, ressaltam que durante o primeiro contato da criança com o lápis e o papel, as primeiras formas gráficas traçadas são rabiscos e a relação com a escrita alfabética ainda é distante, mas, com o passar do tempo, surgem novas representações gráficas elaboradas com maior precisão.

\begin{abstract}
Os primeiros desenhos parecem surgir de forma espontânea e evoluem junto ao processo de desenvolvimento da criança. Os rabiscos iniciais apontam para a extensão do gesto que deixa marcas, mas nem sempre possuem a intenção de transmitir alguma mensagem. Ocorre, então, o aprimoramento das capacidades sensoriais e motoras e o prazer de registrar. Com o tempo essas marcas passam a ter uma intenção e a criança comunica-se por meio delas. (HANAUER, 2013, p. 80).
\end{abstract}

Tendo em vista as ideias de Hanauer (2013), a criança nesse primeiro momento de representação gráfica da escrita ainda não

1 Dicionário online de Português. Porto:7Graus, 2020. Disponível em: https://www.dicio.com.br/grafismo/\#: :text=Significado\%20de\%20Grafismo,tra\%C3\%A7ar\%20uma\%20linha\%2C\%20de\%20desenhar. Acesso em: 2 out. 2020. 
expressa graficamente seus pensamentos de forma legível sobre o papel ou em outra superfície, pois não tem intencionalidade. O desenho surge como algo espontâneo; é uma atividade dotada de prazer pela criança, que está no início do desenvolvimento da escrita. É a partir desse processo inicial do grafismo que a criança começa a nomear os desenhos que são produzidos por ela e tenta traçar letras, e esta relação entre desenho e escrita se faz importante para a fase de alfabetização.

Mediante o desenvolvimento do grafismo, a criança também poderá se aperfeiçoar na escrita, pois "no desenho e na escrita são desenvolvidos aspectos mentais, cognitivos, motores e sociais, já que o indivíduo é um ser social e carrega em sua memória cenas e ações vivenciadas" (YAVORSKI; CAMPOS, 2018, p. 172). Sendo assim, a evolução tanto do desenho como também da escrita possibilita ao indivíduo o desenvolvimento de diversos fatores que estão intrinsicamente relacionados, sendo que dessa forma é possível uma aprendizagem que está para além de codificar e decodificar o código escrito.

Para Ferreira, A. (2015), de acordo com o desenvolvimento do desenho infantil, a criança evolui graficamente, pois no transcorrer da criação dos desenhos podem surgir novas criações artísticas, "adquirindo maior capacidade de representar seres humanos, figuras geométricas, entre outros. Chega um momento que as letras se misturam aos desenhos da criança que elaborando diferentes representações gráficas chegam à escrita alfabética" (FERREIRA, A., 2015, p. 8).

E nesse contexto, por meio do desenho, a criança pode expressar graficamente diferentes visões sobre o seu meio social, fazendo uso dessa linguagem gráfica, sendo esta uma das formas de representação escrita que deve ser trabalhada dentro de sala de aula ou em outros espaços do ambiente escolar por possibilitar à criança proximidade com o código escrito. "O desenho e a escrita, apesar de parecerem distintas, são duas linguagens que interagem e muitas vezes se complementam" (FERREIRA, A., 2015, p. 8). A escrita e o desenho colaboram para o aluno expressar e entender 
o mundo a sua volta; são expressões gráficas que são utilizadas com frequência para interação com as demais pessoas que estão em nosso meio; são linguagens essenciais para uma vida em sociedade.

No entanto, para a criança perceber a importância da escrita para a vida em sociedade e a diferença entre o desenho e a escrita alfabética é um longo processo. Sob essa perspectiva, Cavaton (2010) acrescenta que conforme a criança tem o controle sobre seus movimentos e passa a nomear seus desenhos, ela começa a desenhar com mais precisão; começa a desenhar gatos, cachorros, pessoas, casa, ou seja, a criança a partir desse momento começa a representar elementos do seu dia a dia, passando a ter, dessa forma, maior domínio sobre o código escrito. Vygotsky (2000) pontua que o desenho infantil é uma linguagem gráfica nascida da linguagem verbal. Para o autor, os gestos da criança estão ligados à origem dos signos escritos, sendo que os primeiros entre eles são os rabiscos e desenhos.

Nesse sentido, podemos dizer que as crianças se expressam através da escrita, incialmente a partir dos desenhos, como demonstrado na teoria da psicogênese da escrita de Ferreiro e Teberosky (1999). Dentre as quatro etapas pontuadas pelas autoras (pré-silábica, silábica, silábia-alfabética e alfabética), percebe-se que, num primeiro momento, a criança se expressa a partir de desenhos e/ou garatujas que irão se transformando em letras ao longo do processo de alfabetização.

De acordo com a teoria psicogenética, a criança pensa que pode escrever com desenhos, rabiscos, letras ou outros sinais gráficos, imaginando que a palavra assim inscrita representa a coisa a que se refere no nível pré-silábico. No próximo nível, silábico, a criança já faz uma relação letra e som, mas indica apenas uma letra para cada sílaba. Antes de se tornar alfabética, a criança passa pelo nível intermediário, silábico-alfabético, oscilando numa mesma palavra a representação de uma letra por sílaba e uma letra por fonema. Por fim, o nível alfabético, onde já se faz uma correspondência absoluta de letras e sons. Nesse nível, as crianças já 
O GRAFISMO INFANTIL E SUA RELAÇÃO COM A ESCRITA: uma experiência vivida...

Maria de Fátima Braga Novaes • Cristiane Dias Martins da Costa

são consideradas alfabetizadas, acreditam que as palavras escritas devem representar as palavras faladas, com correspondência absoluta de letras e sons. Já estão alfabetizadas, porém, ainda terão conflitos ao compararem sua escrita alfabética e espontânea com a escrita ortográfica, em que se fala de um jeito e se escreve de outro.

A partir desse contexto, no próximo subitem desta pesquisa apresenta-se dados do campo de pesquisa, que possibilitaram a observação e análise dos desenhos das crianças da turma do $2^{\circ}$ do Ensino Fundamental na Associação Pestalozzi de Codó, Maranhão.

\section{Caracterizações dos componentes da pesquisa}

A Associação Pestalozzi de Codó-MA, conhecida na cidade por Escola Lalá Ramos foi fundada em 22 de maio de 1978 por Terezinha Alvim. A Associação tem como principal objetivo a inclusão de pessoas com deficiência no âmbito educacional. Em 2019, esta instituição de ensino atendia cerca de 203 alunos entre crianças e adolescentes com deficiência auditiva, visual e mental nos turnos matutino e vespertino, porém a pesquisa foi realizada com a turma do $2^{\circ}$ ano do ensino fundamental que constava de dez alunos. A escola tem uma estrutura que atende parcialmente os alunos com deficiência, possuindo 53 funcionários que exercem diversas atividades na escola, como professora de libras, professores de braile, fonoaudiólogo, fisioterapeuta, terapeuta ocupacional, técnico enfermagem, instrutor de informática, vigilantes, professores de educação física, auxiliares de serviços gerais, professores de primeiro ao quinto ano, gestora e secretária.

A instituição realizou no ano de 2019, assim como no decorrer de toda sua trajetória, um trabalho de inclusão no município de Codó-MA, com palestras que integram família e escola, caminhadas pelas principais ruas da cidade em prol da inclusão, além da elaboração e aplicação de projetos de incentivo à leitura que proporcionaram a participação dos pais e responsáveis a partici- 
parem das atividades na escola. Ademais, há o incentivo ao esporte, alguns alunos já foram premiados e dois competiram nas $\mathrm{Pa}$ raolimpíadas em 2019. No quesito dos desafios, ainda se esbarra no preconceito; a escola realiza um trabalho de inclusão, mas ao encaminhar os alunos para o ensino regular, algumas famílias não recebem o apoio necessário para incluir o estudante, e muitos dos alunos pedem para voltar a estudar na Pestalozzi.

Outro desafio tem sido a questão de recursos financeiros, pois a escola é uma instituição filantrópica que se mantém por parcerias e doações. Vale ressaltar que esta é a única instituição de ensino no município com profissionais especializados, com professores de Libras, braile, atendimento de fonoaudiólogo, que trabalham em conjunto para realizar a inclusão dos alunos com deficiência mesmo com o direito assegurado por lei ao atendimento de pessoas com deficiência no sistema regular de ensino.

Nesse contexto, podemos destacar duas leis que asseguram o direito da pessoa com deficiência no sistema regular de ensino: na Constituição Federal Brasileira de 1988 que, no seu artigo 208, inciso III, afirma que o "atendimento educacional especializado aos portadores de deficiência, preferencialmente na rede regular de ensino" (BRASIL, 1988, art. 208) e a Lei de Diretrizes e Bases da Educação Nacional (Lei no 9.394/96), que em seu artigo 59 ressalta que "Os sistemas de ensino assegurarão aos educandos com deficiência, transtornos globais do desenvolvimento e altas habilidades ou superdotação" (BRASIL, 1996, art. 59), e é especificado no inciso III que "professores com especialização adequada em nível médio ou superior, para atendimento especializado, bem como professores do ensino regular capacitados para a integração desses educandos nas classes comuns" (BRASIL, 1996, art. 59).

Mediante essas leis, é posto que a pessoa com deficiência tem o direito a estudar em escolas do ensino regular com professores especializados de forma que a inclusão nas classes comuns seja na prática exercida. Entretanto, como já pontuado dentre os desafios da escola, apenas 20 alunos estavam matriculados em escolas regulares do município em 2019. Alguns dos alunos encaminhados 
O GRAFISMO INFANTIL E SUA RELAÇÃO COM A ESCRITA: uma experiência vivida...

Maria de Fátima Braga Novaes • Cristiane Dias Martins da Costa

para o ensino regular, continuam participando das atividades na Pestalozzi no contra turno.

A Associação Pestalozzi possui sete salas de aula, sendo cinco turmas para o primeiro ano, uma turma do segundo ano e uma para o terceiro ano do Ensino Fundamental no turno matutino. 0 corpo docente da escola é composto por 12 professores no turno matutino, sendo duas professoras do Horário Pedagógico (HP)², uma professora de Educação Física, e os demais, que são nove, lecionam nas turmas do primeiro ao terceiro ano. A maioria dos docentes do turno matutino atuam há mais de dez anos nessa instituição de ensino.

O Projeto Alfabetização e Letramento da Universidade Federal do Maranhão, Campus Codó, realiza ações de extensão na escola desde 2011. Entretanto, a pesquisa em questão se concentra no período de dois anos de atividades desenvolvidas na Pestalozzi que tinham como foco duas ações principais: a contação de história para todos os estudantes do turno matutino e o acompanhamento dos alunos do segundo ano no que se refere às atividades direcionadas à leitura e à escrita.

As contações de história aconteciam uma vez por semana, com duração de 20 minutos. É importante destacar que, durante as contações, sempre foi priorizado a participação dos alunos. No momento da história, eram selecionados alguns alunos para serem personagens nas dramatizações, e essa interação despertava neles o interesse pela atividade. A princípio, as atividades de escrita eram voltadas especialmente para a contação de história; posteriormente, foi realizado um trabalho mais direcionado de leitura e escrita com os alunos da turma mencionada, com várias atividades relacionadas ao processo de alfabetização com foco no letramento, ampliando dessa forma as atividades na escola. O período de acompanhamento, específico na turma do segundo ano, teve início no mês de agosto de 2019, com término em dezembro desse mesmo ano. As atividades eram desenvolvidas uma vez por semana, na sexta-feira, no horário de 7:15 às 11:20.

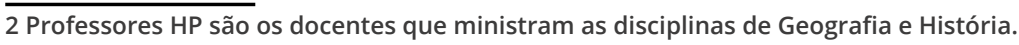


A professora titular da turma observada é pedagoga, tem pós-graduação em Psicopedagogia e atua na docência há 20 anos. Sobre a composição da turma, esta é bem diversificada: contém dez alunos, sendo três meninos e sete meninas, todos têm algum tipo de deficiência, dentre elas, estão: deficiência Física, Intelectual, Múltipla, Paralisia Cerebral, Síndrome de Willians. Dos dez alunos que compõem essa sala, somente três alunos conseguem escrever o próprio nome completo, nomear as cores primárias e algumas formas geométricas oralmente, assim como contar os números de zero a dez; os demais escrevem o nome, mas ainda não é de forma legível.

As situações de desenhos são diversas, entretanto, nesta pesquisa, será dada ênfase aos desenhos direcionados produzidos pelos alunos da turma na qual foi desenvolvida a pesquisa. Nessa perspectiva, as situações de grafismo direcionado a partir da contação de história foram realizadas durante as atividades do projeto "Alfabetização e Letramento na Educação Especial", no período de quatro meses, como mencionado anteriormente.

A proposta do desenho direcionado a partir da contação de história se refere à atividade que a criança explica, por meio do grafismo, o seu entendimento sobre a história contada. O objetivo principal é "analisar como a criança reconstitui, através do desenho a história contada, quais as relações que estabelece entre suas vivências, o referente (história lida) e sua representação no desenho" (PILLAR, 1996, p. 58). Portanto, o grafismo utilizado nesse sentido pode ter objetivos que ultrapassem a forma de escrever. $O$ aluno desenvolve percepção estética ao selecionar as cores a serem aplicadas; relaciona, também, seu desenho com aspectos do seu cotidiano, o que pode contribuir para uma aproximação do código escrito na medida em que o educando escreve o nome da história e dos personagens, fazendo relação destes com a sua vivência (PILLAR, 1996).

É importante citar, como descreve Machado (2008), que mesmo sendo esta uma atividade direcionada, os alunos não copiam os elementos da história como estão nos livros, pois, por meio da 
imaginação, eles recriam a história e dão outras características aos personagens, o que é essencial para a criação e possibilita uma prática não mecanizada, logo, uma interação e troca de conhecimento entre os envolvidos. Ainda segundo o autor, o desenho, de forma geral, contribui para a criança expressar o lúdico, aspectos científicos e fazeres artísticos, tanto o desenho espontâneo como o desenho direcionado.

O lúdico é registrado quando ela representa no papel suas imaginações, sensações, emoções e experiências cotidianas, transformando o ato de desenhar em uma prazerosa brincadeira. Representa o científico quando expressa sua visão de mundo, constituindo assim uma linguagem artística, elaborada por fases que dependerão de seu nível de desenvolvimento psíquico infantil, que varia de criança para criança. $O$ artístico é expresso quando ela se apropria da obra e sente-se livre para criar de forma autônoma.

O processo dialógico entre esses três fatores, posto por Machado (2008), pode desencadear uma aprendizagem que está para além das atividades centradas nas decisões solicitadas pelo educador, pois, na medida em que a criança começa a ter prazer em realizar determinada ação, seja no papel, no chão, na areia e com a utilização de diferentes materiais, ela passa a ver o desenho como uma brincadeira prazerosa, podendo expressar diante dessa tarefa sua visão de mundo de forma sistematizada, de acordo com sua idade e com autonomia. Conforme essa situação, quando a inter-relação entre o desenho e o lúdico, o científico e o artístico acontece durante o processo de ensino, a aprendizagem pode estar sendo estabelecida, além disso, fica nítido que desenhar não é só riscar no papel ou em outras superfícies sem intencionalidade; desenhar é uma linguagem e também conteúdo.

Vale mencionar, como pontua Pillar (1996), que enquanto as crianças fazem os desenhos da contação de história, o mais importante para elas nem sempre é desenhar os personagens principais, mas enfatizar vários detalhes e elementos que são significativos para elas dentro da história, intercalando estes aspectos que 
O GRAFISMO INFANTIL E SUA RELAÇÃO COM A ESCRITA: uma experiência vivida...

Maria de Fátima Braga Novaes • Cristiane Dias Martins da Costa

são significativos com fatores da sua vivência. Tendo em vista a importância do grafismo para a criança de forma integral, no próximo item apresenta-se as experiências com desenhos dos alunos da turma pesquisada que retratam situações por eles vivenciadas, aspectos da realidade, elementos sociais e da imaginação.

\section{A relação dos desenhos das crianças com a psicogênese da língua escrita}

As fases de evolução do desenho perpassam diferentes etapas com nomenclaturas diferentes para cada fase. Antes das análises dos desenhos, é importante destacar que os nomes das crianças nesta pesquisa são fictícios. Além disso, é necessário informar que serão analisados o total de seis desenhos direcionados a partir das histórias contadas.

A escolha por esses grafismos se deu pela relação do desenho com a escrita alfabética em diferentes níveis estabelecida pelos alunos. Por esse motivo, não será apresentado um grafismo para cada aluno, pois somente seis alunos conseguiram representar os dois tipos de escrita, ou seja, o grafismo e a escrita alfabética em suas seções de desenho. Desse modo, quando era solicitado aos alunos um grafismo direcionado, eles desenhavam os elementos que lembravam das histórias contadas na semana; além de desenhar, nomeavam seus desenhos e assim trabalhavam a escrita de forma prazerosa.

Conforme Fayol (2014, p. 33), a escrita "permite a comunicação com os outros, por meio de desenhos, gráficos, mapas, palavras, frases e textos. Também permite representar as situações, relatá-las, descrevê-las, defendê-las - em geral para um destinatário, mas também para si mesmo". Diante disso, a escrita é de suma importância para o ser humano, pois permite uma comunicação entre as pessoas mediante diferentes representações. A seguir, no quadro abaixo, as fases de evolução da escrita alfabética são 
O GRAFISMO INFANTIL E SUA RELAÇÃO COM A ESCRITA: uma experiência vivida...

Maria de Fátima Braga Novaes • Cristiane Dias Martins da Costa

apresentadas, conforme as fases da psicogênese da língua escrita desenvolvidas por Emília Ferreiro e Ana Teberosky (1999).

Conforme Ferreiro e Teberosky (1999, p. 193), no nível 1, “escrever é reproduzir os traços típicos da escrita que a criança identifica como a forma básica da mesma". Neste nível, "a intenção subjetiva do escritor conta mais que as diferenças objetivas no resultado" (FERREIRO; TEBEROSKY, 1999, p. 194), apesar de poder aparecer "tentativas de correspondências figurativas entre a escrita e objeto referido" (FERREIRO; TEBEROSKY, 1999, p. 194). A hipótese central do nível 2 é que para poder ler coisas diferentes deve haver diferença objetiva nas escritas. No nível 3, hipótese silábica, existe a tentativa de dar um "valor sonoro a cada uma das letras que compõem uma escrita" (FERREIRO; TEBEROSKY, 1999, p. 209). Por fim, o nível 4, representado pela passagem da hipótese silábica para alfabética, faz com que a criança descubra a necessidade de fazer uma análise que vai além da sílaba e é o conflito entre as formas gráficas que propõe a leitura. A seguir, apresenta-se as características principais para cada nível segundo as concepções de Rosseto (2017).

\section{Quadro 1 - Fases de Evolução da Escrita}

\begin{tabular}{|c|l|}
\hline $\begin{array}{c}\text { Níveis da escrita } \\
\text { alfabética }\end{array}$ & \multicolumn{1}{|c|}{ Principais características } \\
\hline 1- Pré-silábico & $\begin{array}{l}\text { A criança quando está neste nível ainda não consegue estabelecer a dife- } \\
\text { rença entre letra e desenho, os rabiscos estão presentes de forma acen- } \\
\text { tuada, atribui também, a mesma grafia para palavra diferente, as pseudo } \\
\text { letras e números fazem parte deste nível da escrita. }\end{array}$ \\
\hline Silábico & $\begin{array}{l}\text { É o início da articulação entre grafema e fonema pela criança, mas a criança } \\
\text { entende que para cada sílaba da palavra deve-se atribuir uma letra. }\end{array}$ \\
\hline 2- Silábico alfa- & $\begin{array}{l}\text { É a fase de transição do nível silábico para o alfabético. Neste caso, já é } \\
\text { atribuído pela criança mais de uma letra para representar a silaba de uma } \\
\text { palavra. }\end{array}$ \\
\hline bético & $\begin{array}{l}\text { Neste último nível a criança já consegue fazer análises da sua escrita, mas } \\
\text { podem surgir outras dificuldades, sobretudo na parte da ortográfica. }\end{array}$ \\
\hline
\end{tabular}

Fonte: Elaborado pelas autoras a partir de Rosseto (2017).

Partindo disso, nos grafismos apresentados a seguir, as crianças estabeleceram uma relação do desenho com os níveis de evolução da escrita, porém, é importante destacar que os alunos da 
O GRAFISMO INFANTIL E SUA RELAÇÃO COM A ESCRITA: uma experiência vivida...

Maria de Fátima Braga Novaes • Cristiane Dias Martins da Costa

turma na qual foi desenvolvida a pesquisa ainda não estão no nível alfabético. Desse modo, a análise dos desenhos consiste somente nos três primeiros níveis de aquisição da escrita alfabética. As duas primeiras imagens de desenho direcionado selecionadas para análise são de autoria das alunas Safira e Esmeralda. O desenho de Safira foi criado no dia 25 de outubro de 2019; a produção de Esmeralda foi realizada no dia 22 de novembro do mesmo ano.

Figura 1- Desenho direcionado da aluna Safira

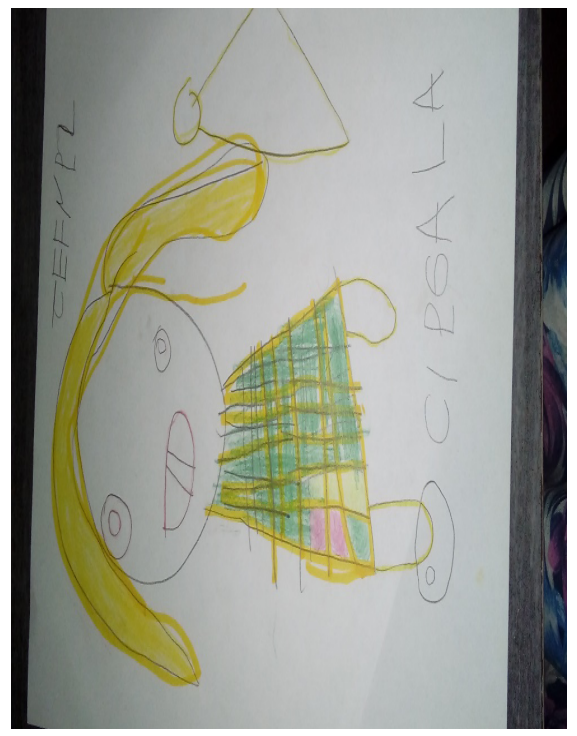

Fonte: SAFIRA (2019).

Figura 2 - Desenho direcionado da aluna Esmeralda

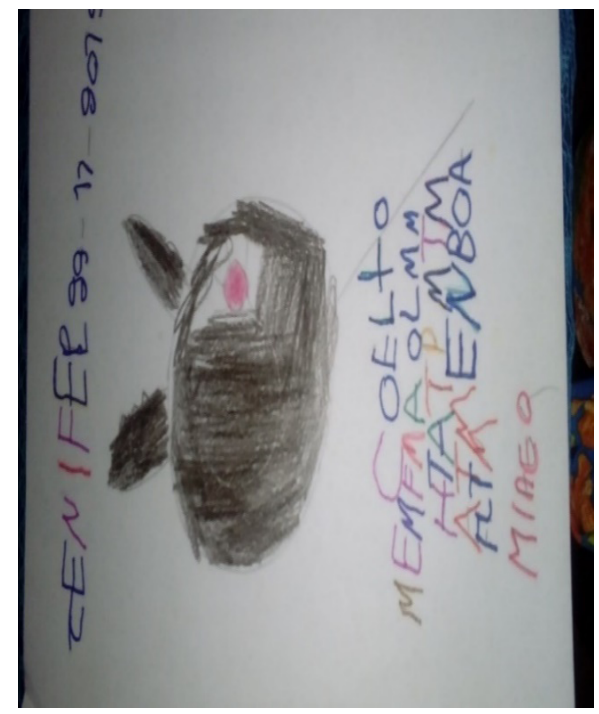

Fonte: ESMERALDA (2019). 
Na Figura 1, a aluna Safira expôs o desenho a partir da história da Cinderela. A aluna desenhou uma menina com vários elementos; no rosto ela fez a boca e os olhos, fez também o cabelo um pouco longo e pintou de cor amarela. Como roupa, ela fez um vestido e coloriu nas cores verde, amarelo e rosa; nas pernas, somente em uma ela fez um sapato; faltaram alguns elementos, como braços e mãos, nariz e orelhas. Quando a aluna fez a socialização do seu desenho para turma, descreveu que a menina é a personagem Cinderela da história. Com a sua narrativa ficou explicado o motivo dela ter pintado o cabelo de amarelo e ter desenhado somente um dos sapatos. Safira relatou que a personagem na história é loira e branca, seu vestido é longo e por isso fez um vestido lindo, e desenhou só um sapato porque a Cinderela perdeu o outro sapato.

Além da comunicação visual através do desenho, a aluna traçou, sobre o papel, algumas letras; na parte inferior do desenho, ela escreveu o nome da personagem como "CIPGALA = Cinderela". Com essa escrita, pode-se perceber que a aluna escreveu o nome Cinderela com algumas alterações: a primeira e a última sílaba da palavra têm relação grafema-fonema, porém, as outras letras estão escritas de forma desordenada, não apresentam relação entre letra e som. Desse modo, Safira demonstra que está na fase pré-silábica, ou seja, sua escrita apresenta mais características do primeiro nível de aquisição da escrita; não existe ainda uma correspondência entre letra e som de forma mais precisa em sua escrita.

A Figura 2 apresenta o desenho da aluna Esmeralda referente à história da Menina bonita do laço de fita, de Ana Maria Machado. Esmeralda fez o grafismo de um coelho. Os motivos que a levaram a fazer esse desenho foram vários, como ela relatou, e dentre eles, citou que este animal é bonito e muito fofo. Além do desenho, a aluna traçou várias letras de forma desordenada, com exceção da palavra "Coelho", escrita da seguinte forma: "COELTO". Nesta palavra é estabelecido uma relação entre letra e som, mas a aluna trocou a letra $\mathrm{H}$ pela letra $\mathrm{T}$. 
O GRAFISMO INFANTIL E SUA RELAÇÃO COM A ESCRITA: uma experiência vivida...

Maria de Fátima Braga Novaes • Cristiane Dias Martins da Costa

Nas demais palavras, conforme é observado na figura, não existe uma relação entre letra e som, "MEMFMA OLMM; HTATPMTM; ATMENBOA; RTM; MIAGO". Nesse sentido, podemos dizer que esta aluna demonstra estar na hipótese Pré-silábica, no primeiro nível de aquisição da escrita alfabética. Por algum motivo ela conhecia visualmente a palavra "Coelho", por isso a escreveu estabelecendo uma relação entre grafema e fonema. Na sequência, os desenhos são de autoria das alunas Pérola e Turmalina, seção de desenho que aconteceu no dia 18 de outubro de 2019 a partir da contação da história "Cachinhos Dourados".

\section{Figura 3 - Desenho direcionado da aluna Pérola}

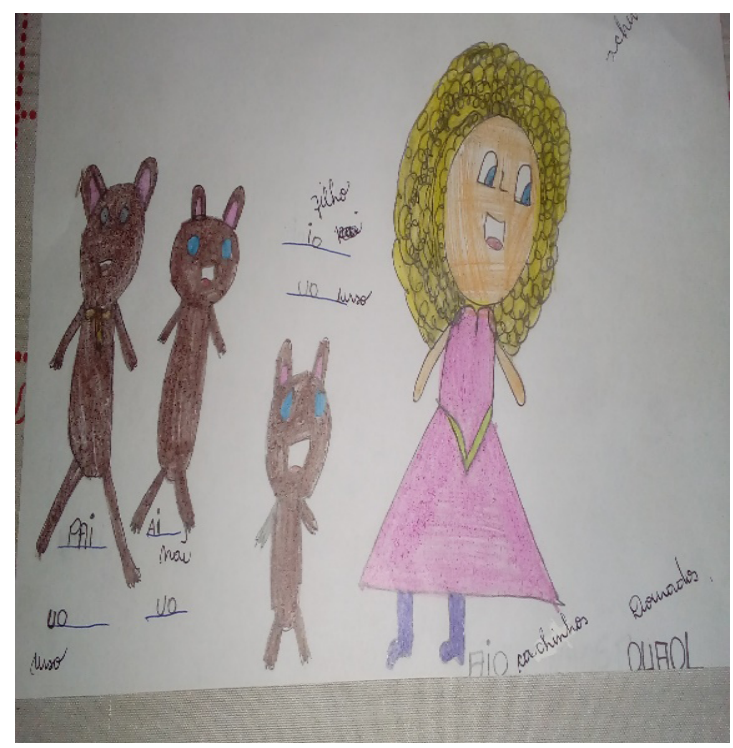

Fonte: PÉROLA (2019). 
Figura 4 - Desenho direcionado da aluna Turmalina

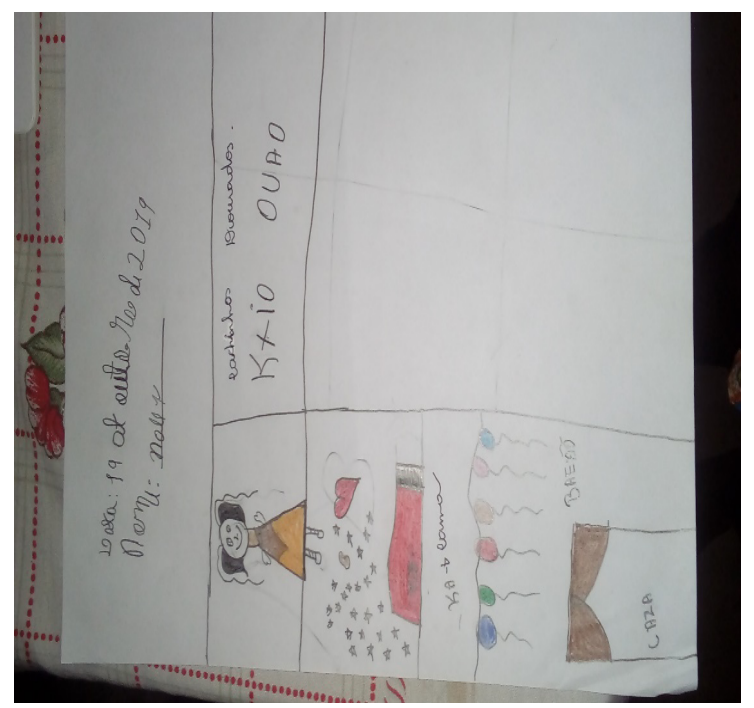

Fonte: TURMALINA (2019).

Sobre a análise dos desenhos das figuras, os personagens representados por Pérola foram Cachinhos Dourados e os três ursos presentes na história. Os desenhos são bem detalhados; a personagem principal, Cachinhos Dourados, está com cabelo bem enrolado e pintado na cor amarelo; os olhos, a boca e o nariz estão bem delineados e pintados; a roupa é um vestido rosa acentuado com detalhe verde na cintura; nos pés a personagem usa botas na cor lilás; a pele foi pintada na laranja; nos braços ela não desenhou as mãos. Em relação aos ursos, estes foram pintados na cor marrom, mas com características diferentes. Eram três ursos: urso pai, com boca pequena e arredondada, orelha com detalhes na cor rosa, olhos pretos e com gravata na cor laranja; ursa mãe, com orelhas nas cores marrom e rosa, boca quadrada, com língua vermelha e olhos azuis; urso filho, também com orelhas na cor rosa e marrom, a boca mais arredondada e grande, e olhos azuis. É notório que a aluna estabeleceu um tamanho para cada urso: o pai é o maior; a mãe tem tamanho menor que o do pai; o urso filho menor que a mãe e o pai.

Mediante a análise da escrita de Pérola, esta se encontra na hipótese silábica, no segundo nível de aquisição da escrita. Em relação ao nome da história, Cachinhos Dourados foi escrita da 
seguinte forma: "AIO = cachinhos / OUAO = dourados". Já a palavra "Pai" a aluna consegue escrever corretamente, porém, nas demais palavras, foi mantida a mesma forma de escrita das demais palavras apresentadas; para cada sílaba, foi atribuído letra com valor sonoro correspondente, sendo escrita desta forma as palavras: “UO = urso/ AI = mãe/ IO = filho". Conforme o observado, $a$ aluna Pérola já é capaz de fazer a associação entre letra e som na maioria das palavras escritas, com exceção da palavra "Mãe". É importante destacar que na escrita de Pérola as letras representadas nas sílabas são somente as vogais. Por apresentarem o som mais forte na palavra, as vogais se tornam mais fáceis para a criança no início da aquisição da linguagem escrita.

\begin{abstract}
Neste nível, o aluno dá um salto qualitativo: cada letra vale por uma sílaba, uma vez que esta letra pode ser representada com um valor sonoro estável, ou não. Caso o aluno não empregue o valor sonoro convencional para cada letra, segue-se, durante a representação escrita do educando, a exigência de se dispor uma letra para notar uma sílaba. Entretanto, há também outras crianças que, além de escreverem as palavras com a preocupação de quantificá-las corretamente, atribuem o valor sonoro convencional a cada letra representada, em suas escritas. (LUNA; SILVA, 2013, p. 39).
\end{abstract}

Com relação à Turmalina (Figura 4), a aluna representou graficamente outros personagens da história além da personagem Cachinhos Dourados. No momento de partilha com a turma sobre a história do desenho, a aluna falou que desenhou uma casa e que dentro da casa estava a personagem principal da história, Cachinhos Dourados, com cabelo preto e vestido na cor laranja com marrom. As mãos e os pés da personagem foram desenhados, mas não pintados, faltando dessa forma alguns detalhes. Também foi desenhado um dos cômodos da casa, o quarto com uma cama. A aluna acrescentou várias estrelas; a porta da casa desenhada 
O GRAFISMO INFANTIL E SUA RELAÇÃO COM A ESCRITA: uma experiência vivida...

Maria de Fátima Braga Novaes • Cristiane Dias Martins da Costa

tem alguns detalhes na cor marrom e alguns balões coloridos na parede, como relatou Turmalina.

A escrita da aluna Turmalina, conforme observado, faz parte do terceiro nível de aquisição da escrita, hipótese silábico-alfabético, pois a aluna faz relação entre grafema e fonema de forma mais aprofundada e com maior domínio da relação grafema-fonema nas palavras. Nesse nível, a criança começa a atribuir mais de uma letra para compor uma sílaba. Nesse contexto, podemos observar como Turmalina utilizou a escrita alfabética em sua seção de desenho. Para o nome da história, Turmalina escreveu desta forma: "KXIO = cachinhos / OUAO = dourados". Contata-se que, para cada sílaba, a aluna atribui uma letra ou mais de uma letra, assim como nas palavras "KA = cama / AEÃO = balão / CAZA = casa", nas quais se verifica que em algumas sílabas a aluna não relaciona letra e som de forma correta.

Em suma, o processo de evolução gráfica de Pérola e Turmalina apresenta algumas características descritas por Luna e Silva (2013), pois as alunas estabelecem em algumas palavras relação entre grafema e fonema, assim como atribuem uma letra ou mais letras para cada sílaba. No entanto, em algumas palavras, ambas não relacionam a letra com som, escrevendo letras aleatórias. Em continuidade, os grafismos apresentados a seguir foram produzidos também no dia 22 de novembro de 2019. Os autores são Safira e Jaspe; os desenhos são referentes a história "Menina Bonita do Laço de Fita". 
O GRAFISMO INFANTIL E SUA RELAÇÃO COM A ESCRITA: uma experiência vivida... Maria de Fátima Braga Novaes • Cristiane Dias Martins da Costa

Figura 5 - Desenho direcionado da aluna Safira

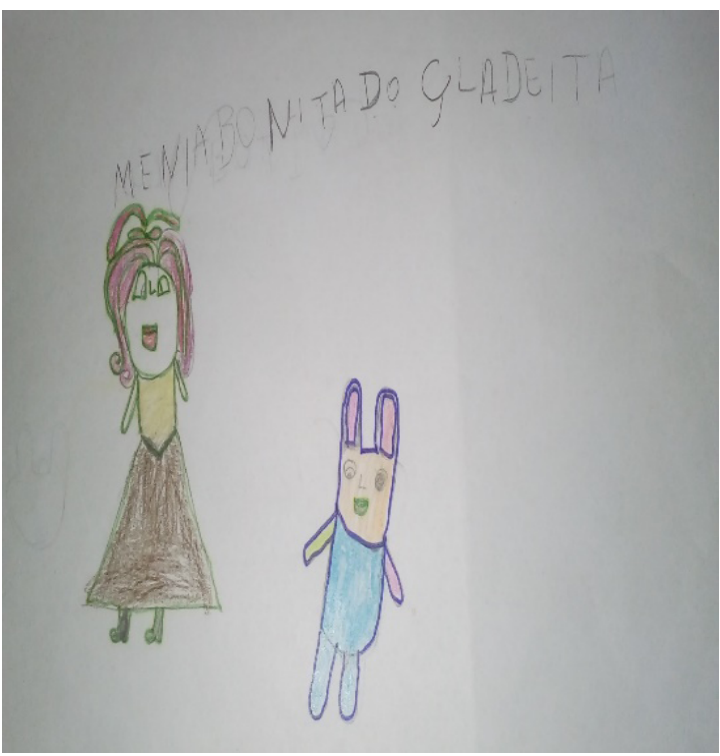

Fonte: SAFIRA (2019).

Figura 6 - Desenho direcionado do aluno Jaspe

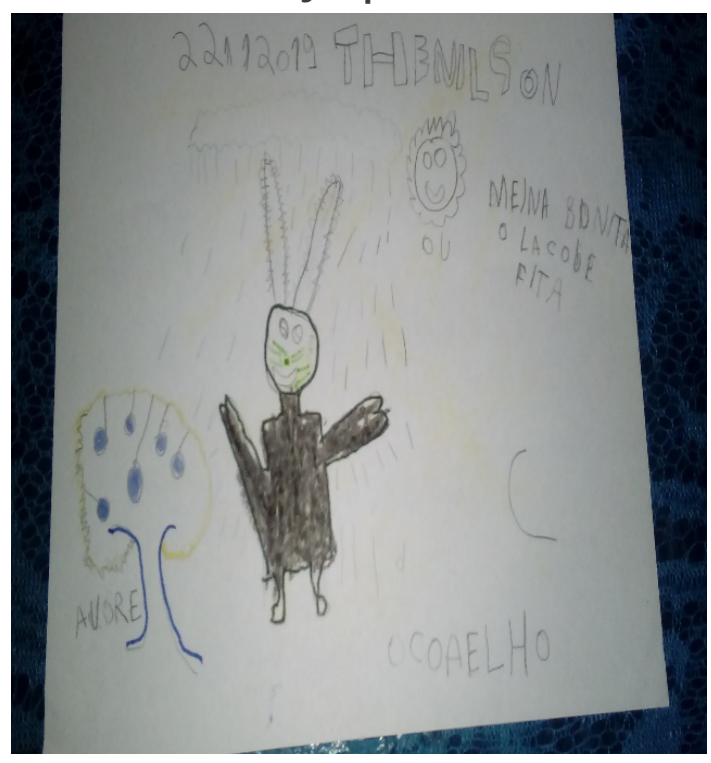

Fonte: JASPE (2019).

Em sua criação gráfica (Figura 5), Safira desenhou dois personagens da história, a menina bonita e o coelho. Na menina ela fez um contorno na cor verde que cobre toda a personagem; os cabelos 
pintou com a cor rosa; o vestido da personagem foi pintado nas cores amarelo e marrom; nos braços faltou acrescentar as mãos; para os pés fez uma bota; para pintar o tom de pele da menina, ela utilizou a cor laranja, diferente do tom de pele apresentado na história. Ao desenhar o Coelho, Safira utilizou várias cores: primeiramente contornou o animal na cor lilás; a boca coloriu na cor verde; nos olhos e nariz utilizou somente o lápis de escrever; pintou as oreIhas de preto com rosa; pintou o rosto do Coelho da cor laranja; a barriga e as pernas foram pintadas na cor azul; os braços pintou de rosa e verde; dessa forma, o Coelho ficou todo colorido. Durante a socialização, a aluna proferiu que desenhou somente os dois personagens da história que mais gostou, a menina bonita e o Coelho, e acrescentou ainda que não conhecia essa história; em suma, Safira não falou muito sobre seu desenho.

A Figura 6, também relacionada à história "Menina Bonita do Laço de Fita", mostra que o grafismo do aluno Jaspe está cheio de detalhes. No momento de socialização com a turma, o aluno falou que desenhou o sol com olhos e boca, desenhou o coelho e o pintou na cor preta do pescoço para baixo, deixou a cabeça e as orelhas na cor branca, e que o motivo do coelho estar dessa forma é que ele era branco e se pintou de preto para agradar a menina bonita, mas caiu uma forte chuva e aos poucos ficou branco novamente. Jaspe ressaltou que ao lado do coelho tem uma árvore, é um pé de jabuticaba cheio de frutas.

Diante dos desenhos analisados, observa-se que ao desenharem os dois alunos expressam graficamente suas lembranças da história, o que é essencial para o desenvolvimento integral da criança, pois as atividades de desenho, sejam espontâneas ou direcionadas, contribuem para aprendizagem da criança (CARVALHO, 2015). No que concerne à escrita alfabética, a aluna Safira consegue relacionar em algumas palavras grafemas e fonemas, mas não consegue relacionar em todos os seus escritos essa conexão entre letra e som. Em sua escrita nesse desenho ela escreveu o nome da história desta forma: "MENIA = menina / BONITA = bonita / DO = do / ÇLA= laço / DE = de / ITA = fita". Assim, a aluna consegue 
O GRAFISMO INFANTIL E SUA RELAÇÃO COM A ESCRITA: uma experiência vivida...

Maria de Fátima Braga Novaes • Cristiane Dias Martins da Costa

estabelecer coerência entre letra e som em algumas das palavras, como está exposto.

Do mesmo modo, o aluno Jaspe escreve o nome da história desta forma: "MEINA = menina / BONITA = bonita $/ \mathrm{O}=$ do $/ \mathrm{LACO}=$ laço $/ \mathrm{bE}=$ de (o aluno trocou a letra d pela letra b) $/$ FITA = fita. Nos outros elementos da história que ele também desenhou, como sol, árvore e coelho, a escrita ficou assim: "OU = sol, AVORE = árvore, COAELHO= coelho". Nesse sentido, conforme as ideias de Luna e Silva (2013), esse tipo de escrita apresentado pelos alunos se encontra no terceiro nível de aquisição da escrita, na fase de transição da hipótese silábica para hipótese silábico - alfabético. Esse nível é caracterizado por grandes conflitos,

Neste momento, a criança percebe que estabelecer uma letra para cada sílaba não é suficiente para representar uma palavra e assim, começa a dispor mais letras, tornando a tarefa muito complexa, devido ao fato de implicar uma reflexão mais sofisticada, acerca da palavra a ser notada. (LUNA; SILVA, 2013, p. 39).

Compreende-se, portanto, que quando a criança chega ao nível de aquisição do código alfabético, sua escrita passa a ser mais assimilada pelo educador e pela própria criança, pois passa a ser atribuída mais de uma letra para composição de uma sílaba e, dessa forma, sua evolução gráfica se aproxima ainda mais da escrita alfabética.

\section{Considerações finais}

A elaboração da presente pesquisa nos leva a refletir sobre aspectos importantes acerca do desenho infantil dentro do ambiente escolar e social da criança sob diferentes perspectivas, pela contribuição desse recurso gráfico para compreensão da vida dos nossos antepassados, por auxiliar o professor na compreensão de 
seus alunos e por ser um recurso didático importante durante a fase de transição da representação icônica para a não icônica no período de alfabetização. Dessa forma, quando começa a escrever, os primeiros traços da criança são as representações gráficas icônicas, ou seja, desenhos; a partir dessa primeira forma de comunicação, surgem as primeiras letras. Logo de início não existe relação entre grafemas e fonemas; o desenho, nesse sentido, é a base para o desenvolvimento da escrita.

Sendo assim, o grafismo, nessa perspectiva, contribui para o processo de ensino da criança logo nos primeiros anos de escolarização, pois é mediante o desenho que a criança externa graficamente, sobre o papel ou em outras superfícies, suas necessidades, sentimentos, além de contribuir com aspectos cognitivos, motores, sociais e emocionais. Diante desses argumentos, podemos perceber que o desenho infantil é de salutar importância para a criança, logo, essa atividade não pode ser praticada dentro da sala de aula sem intencionalidade, somente para entreter o aluno, pois como foi explicitado, o grafismo é um importante recurso para a criança e para o professor. Nesse viés, é importante destacar que a experiência com o desenho direcionado desenvolvido com as crianças do segundo ano dos anos iniciais do Ensino Fundamental foi significativa para as crianças, pois esta é uma atividade que todos da turma gostam de fazer; se fosse permitido, eles passavam a aula inteira desenhando e ouvindo as contações de história.

Nesse ensejo, as histórias contadas contribuíram para o desenvolvimento de uma prática pedagógica mais dialógica, pois ao passo que as histórias eram contadas, o diálogo era estabelecido, as leituras de imagens despertavam imaginação e o desejo em aprender a ler era aguçado por essas crianças. Neste momento, elas eram capazes de se reconhecerem dentro das histórias, pois durante a socialização dos desenhos sempre eram externados os personagens ou elementos que faziam parte de suas vivências e, dessa forma, era intercalado fatos vivenciados nas histórias com a própria realidade do educando, dando novos sentidos à vida. 
O GRAFISMO INFANTIL E SUA RELAÇÃO COM A ESCRITA: uma experiência vivida... Maria de Fátima Braga Novaes • Cristiane Dias Martins da Costa

Dessa forma, durante os dois anos de convivência na escola, especialmente no período das atividades em sala de aula, foi possível compreender a relação do grafismo com a escrita desses alunos, como também as formas de se expressar por meio do grafismo. Ao analisar os resultados obtidos, podemos ressaltar que a maioria dos alunos da turma do segundo ano fazem relação da escrita alfabética com desenhos; além disso, foi possível identificar as fases de evolução do grafismo em que esses alunos se encontravam, quais as dificuldades apresentadas por eles em relação à escrita até do próprio nome, como já foi pontuado no decorrer desta pesquisa.

Ademais, durante as aulas, dois dos dez alunos dessa turma, Pérola e Jaspe, leram algumas palavras. A alegria desses alunos durante o momento da leitura foi emocionante, pois eles não estavam acreditando que estavam conseguindo ler, o que nos mostrou que utilizar o grafismo nas aulas com fins pedagógicos pode proporcionar resultados positivos. Diante desse fato, foi possível perceber que a realização desta pesquisa possibilitou aprender a aprender, ou seja, esses alunos nos incentivaram a buscar novas metodologias para ensinar, o que contribui para a nossa formação, tanto profissional como pessoal, pois contribuir com a educação desses alunos foi uma experiência enriquecedora.

\section{Referências bibliográficas}

\section{BRASIL. Ministério da Educação. Lei de Diretrizes e Bases da}

Educação Nacional. Lei n. 9394, 20 de dezembro de 1996. Brasília: MEC, 1996.

BRASIL. Constituição da República Federativa do Brasil. Brasília, DF: Senado Federal, 1988.

CARVALHO, Valéria Luzia Fernandes. O desenho como forma de ex-

pressão no Ensino de Artes Visuais. 2015. 45f. Trabalho de Conclusão 
O GRAFISMO INFANTIL E SUA RELAÇÃO COM A ESCRITA: uma experiência vivida... Maria de Fátima Braga Novaes • Cristiane Dias Martins da Costa

de Curso (Especialização em Ensino de Artes Visuais) - Escola de Belas Artes, Universidade Federal de Minas Gerais, Belo Horizonte, 2015. CAVATON, Maria Fernanda Farah. A mediação da fala, do desenho e da escrita na construção de conhecimento da criança de seis anos. 2010. 173f. Tese (Doutorado em Processos de Desenvolvimento Humano e Saúde) - Instituto de Psicologia, Universidade de Brasília, Brasília, 2010.

FAYOL, Michel. Aquisição da escrita. São Paulo: Parábola Editorial, 2014.

FERREIRA, Ana Patrícia. A importância do ensino de artes visuais na educação infantil. 2015. 39f. Trabalho de Conclusão de Curso (Especialização em Ensino de Artes Visuais) - Escola de Belas Artes, Universidade Federal de Minas Gerais, Belo Horizonte, 2015.

FERREIRA, Carlos Augusto Lima. Pesquisa quantitativa e qualitativa: perspectiva para o campo da educação. Revista Mosaico, Vassouras, v. 8, n. 2, p. 173-182, 2015.

FERREIRO, Emília; TEBEROSKY, Ana. Psicogênese da língua escrita. Porto Alegre: Artmed, 1999.

HANAUER, F. Riscos e Rabiscos- o desenho na educação infantil. Perspectiva, Erechim, v. 37, n. 140, p. 73-82, dez. 2013.

LUCAS, Maria Angélica Olivo Francisco; CUSTÓDIO, Tatiana; VIDOTTI, Thaís Tono. O papel do desenho no processo de apropriação da escrita. In: SEMANA DE PEDAGOGIA DA UEM, 1., 2012, MARINGÁ. Anais [...]. Maringá: Universidade Estadual de Maringá, 2012. p. 1-6.

LUNA, Franciele da Silva; SILVA, Ruth André. Psicogênese da língua escrita: o processo de ensino e aprendizagem de alfabetização no $1^{\circ}$ ano do ensino fundamental. 2013. 91f. Trabalho de Conclusão de Curso (Licenciatura em Pedagogia) - Centro Universitário Católico Salesiano Auxilium, Lins, São Paulo, 2013.

MACHADO, Lucimar da Silveira Vieira. Desenho - Pré-estabelecido e Espontâneo. Trabalho de Conclusão de Curso (Licenciatura em Pedagogia) - Universidade do Estado do Rio de Janeiro, Rio de Janeiro, 2008. 
O GRAFISMO INFANTIL E SUA RELAÇÃO COM A ESCRITA: uma experiência vivida...

Maria de Fátima Braga Novaes • Cristiane Dias Martins da Costa

MARQUES, Carina Domingues. A Arte Rupestre. Monções UFMS, Mato Grosso do Sul, v. 3, n. 4, p. 21-36, fev. 2016.

PAIVA, Vera Lúcia Meneses de Oliveira. Manual de pesquisa em estudos linguísticos. São Paulo: Parábola, 2019.

PILLAR, A. D. Desenho e construção de conhecimento na criança. Porto Alegre: Artes Médicas, 1996.

ROSSETO, Alessandra Dedéco Furtado. Sondagem digital da escrita de crianças em fase alfabetização: uma abordagem tecnológica a partir da psicogênese da língua escrita. 2017. 73f. Dissertação (Mestrado em Educação) - Programa de Pós-Graduação em Ensino de Ciências Humanas, Sociais e da Natureza, Universidade Tecnológica Federal do Paraná, Londrina, 2017.

SEVERINO, Antônio Joaquim. Metodologia do trabalho científico. 23. ed. rev. e atual. São Paulo: Cortez, 2007.

VYGOTSKY, Lev. A pré-história da linguagem escrita. In: VYGOTSKY, Lev. (org.) Formação social da mente. São Paulo: Martins Fontes, 2000. p. 140-157.

WIELEWICKI, Vera Helena Gomes. A pesquisa etnográfica como construção discursiva. Acta Scientiarum, Maringá, v. 23, n. 1, p. 27-32, 2001. YAVORSTI, Rosely; CAMPOS, M. A. S. A importância do desenho infantil para o desenvolvimento da escrita no ensino fundamental. Revista GeoPantanal, Pantanal, v. 13, n. 25, p. 165-180, jul. /dez. 2018. 